\title{
Analysis of Eco-Tourism Climate Resources in Xingwen, China Based on the Comfort Index and the Negative Air (Oxygen) Ion
}

\author{
Meng Yuan 1,2,3, Xinchao Liu ${ }^{1,3}$, Jie Guo ${ }^{1,3}$, Yao Huang1,3, Wenwen Song1,3 \\ ${ }^{1}$ Key Laboratory of Sichuan Province for Heavy Rain and Drought Flood Disasters in Plateaus and Basins, Chengdu, China \\ ${ }^{2}$ Sichuan Rural Economic Information Center, Chengdu, China \\ ${ }^{3}$ Sichuan Meteorological Service Center, Chengdu, China \\ Email: *nikki147@163.com
}

How to cite this paper: Yuan, M., Liu, X. C., Guo, J., Huang, Y., \& Song, W. W. (2021). Analysis of Eco-Tourism Climate Resources in Xingwen, China Based on the Comfort Index and the Negative Air (Oxygen) Ion. Journal of Geoscience and Environment Protection, 9, 154-163.

https://doi.org/10.4236/gep.2021.93009

Received: January 1, 2021

Accepted: March 20, 2021

Published: March 23, 2021

Copyright $\odot 2021$ by author(s) and Scientific Research Publishing Inc. This work is licensed under the Creative Commons Attribution International License (CC BY 4.0).

http://creativecommons.org/licenses/by/4.0/

\begin{abstract}
The present work investigates an analysis of Eco-Tourism Climate Resources in Xingwen, China based on the Comfort Index and Negative Air (Oxygen) Ion ("NAI" for short in this article) concentration. The daily temperature, precipitation, wind speed, sunshine hours, and relative humidity data of the Xingwen National Meteorological Station from 1999 to 2018, as well as the NAI data of Feiwu Cave station and Shoushan Lake station in Xingwen of 2018 were used in this study. Based on the analysis of the characteristics of basic meteorological elements, the index of climate comfort of human living environment and the NAI variation in Xingwen, the eco-tourism climate resources in this area were evaluated comprehensively. The results show that: The climate is mild, the precipitation is abundant and the seasonal variation trend of precipitation and heat is similar in the study area. The annual average temperature of this area is $17.8^{\circ} \mathrm{C}$, the annual average precipitation is $1096 \mathrm{~mm}$, the annual average precipitation days are 186 days, the annual average relative humidity is $81 \%$, the annual average wind speed is $1.3 \mathrm{~m} / \mathrm{s}$, and the annual average sunshine hours are $999 \mathrm{~h}$. The living environment comfort level reaches the "comfort" level for 6 months per year. In addition, the concentration of NAI in Xingwen remains at the highest level 7 throughout the year, and the rate of good air quality is extremely high. Overall, the study area has high-quality ecological climate resources that are conducive to the development of forest recuperation, leisure and vacation and other ecological tourism activities.
\end{abstract}

\section{Keywords}

Climate Resources, Eco-Tourism, Comfort Index, NAI 


\section{Introduction}

Temperature, sunshine, wind speed, relative humidity, rainfall, air freshness and other conditions have a comprehensive impact on the experience of tourists. In recent years, the public meteorological services are not only limited to the forecast of meteorological elements, but also related to the human feelings of the forecast and service. The comfort index evaluates the comfortable feeling of human body in different climatic conditions. Considering the comprehensive effect of temperature, humidity, wind speed and other meteorological factors on human body, the general population's feelings towards the external meteorological environment can be quantitatively described with an index. Many experts and scholars (Hougthton \& Yaglou, 1923; Siple\& Passel, 1945; Thom, 1959; Terjuny, 1966; Gagge et al., 1970; Kalkstein \& Valimont, 1986; Zhou, 1999) began to study the human comfort index since the early last century. Thom proposed the discomfort index in 1959 (Thom, 1959). Terjuin proposed the concept of climate comfort index (Terjuny, 1966). Nikolopoulou \& Lykoudis studied the thermal comfort of cities in different European countries (Nikolopoulou \& Lykoudis, 2006). Barradas used the temperature and relative humidity series to calculate the comfort index of 5 parks in Mexico City and their surroundings (Barradas, 1991). Wang et al. designed a calculation method for human comfort based on the golden section method (Wang et al., 2013). Xu \& Zhu made a detailed analysis of body surface temperature, discomfort index and clothing index (Xu \& Zhu, 2000). Yan \& Shen proposed seven design methods for environmental meteorological index and human comfort index (Yan \& Shen, 2005). The above different comfort index calculation methods have their own advantages and disadvantages. We selected the Index of climate comfort of human living environment for calculation, which is actually commonly used by the China Meteorological Administration in recent years.

The research area Xingwen is located in the southeast of Sichuan Province, China, which is a golden tourism node and transportation hub in Sichuan, Yunnan, Guizhou and Chongqing. Xingwen has a long history and is the place where the ancient Bo people multiplied and eventually died out. It is also an area where the Miao people in Sichuan Province are concentrated, with ethnic minorities accounting for $11 \%$ of the total population. The Xingwen landform is a typical basin and mountain topography. Xianfeng Mountain divides the whole area into the north and south in the middle, and the altitude ranges from more than 200 meters to 1800 meters. The area has a large vertical gradient and remarkable three-dimensional climate characteristics. Studying the suitability of eco-tourism climate resources in this area is of great significance for guiding tourists to travel, developing and improving tourism products, and expanding the health and tourism market.

\section{Materials and Methods}

\subsection{Data}

The meteorological data of Xingwen national automatic meteorological station 
from 1999 to 2018 were used in the study. We selected daily data of temperature, precipitation, wind speed, relative humidity and sunshine hours for statistical analysis. The NAI data of Feiwu Cave station and Shoushan Lake station in Xingwen of 2018 were also used (Table 1).

\subsection{Methodology}

\section{Season Division}

According to the classification of climate statistics in China, we define March to May as spring, June to August as summer, September to November as autumn, and December to February as winter.

\section{Index of Climate Comfort of Human Living Environment}

The provisions of the "People's Republic of China National Standard GBT27963 2011 Human Living Environment and Climate Comfort Evaluation" were used in this research, the calculation method and the classification standard of human living comfort level are as follows (Table 2).

The Temperature-Humidity Index $(I)$ is an index that describes the human body's comprehensive perception of environmental temperature and humidity. Among them, temperature is the main factor. When the temperature is suitable, the influence of humidity on the comfort of the human body is not significant, and when the temperature is too high, the influence of humidity on the human body tends to be significant. The Temperature-Humidity Index $(I)$ is calculated as follows (Tang et al., 2008):

Table 1. Stations information.

\begin{tabular}{ccccc}
\hline Station Name & Latitude $\left({ }^{\circ} \mathrm{N}\right)$ & Longitude $\left({ }^{\circ} \mathrm{E}\right)$ & Altitude $(\mathrm{m})$ & Station Type \\
\hline Xingwen & 28.32 & 105.23 & 399 & Meteorological station \\
Feiwu Cave & 28.55 & 105.14 & 930 & NAI station \\
Shoushan Lake & 28.31 & 105.05 & 998 & NAI station \\
\hline
\end{tabular}

Table 2. Index Grade of climate comfort of human living environment.

\begin{tabular}{|c|c|c|c|c|}
\hline Grade & $\begin{array}{l}\text { Body } \\
\text { feeling }\end{array}$ & $\begin{array}{c}\text { Temperature-Humidity } \\
\text { Index }(I)\end{array}$ & $\begin{array}{l}\text { Wind-Efficiency } \\
\text { Index }(K)\end{array}$ & $\begin{array}{c}\text { Description of } \\
\text { the Feeling } \\
\text { of Healthy People }\end{array}$ \\
\hline 1 & Freeze & $<14.0$ & $<-400$ & $\begin{array}{l}\text { Feel very cold and } \\
\text { uncomfortable }\end{array}$ \\
\hline 2 & Chill & $14.0-16.9$ & $-400--300$ & $\begin{array}{l}\text { Feel chill and less } \\
\text { comfortable }\end{array}$ \\
\hline 3 & Comfortable & $17.0-25.4$ & $-299--100$ & $\begin{array}{c}\text { Feel comfortable and } \\
\text { acceptable }\end{array}$ \\
\hline 4 & Hot & $25.5-27.5$ & $-99--10$ & $\begin{array}{c}\text { Feel a bit hot and less } \\
\text { comfortable }\end{array}$ \\
\hline 5 & Stuffy Hot & $>27.5$ & $>-10$ & $\begin{array}{l}\text { Feel stuffy hot and } \\
\text { uncomfortable }\end{array}$ \\
\hline
\end{tabular}




$$
I=T-0.55 \times(1-R H) \times(T-14.4)
$$

In the formula, $I$ represents the temperature and humidity index, $T$ is the average temperature $\left({ }^{\circ} \mathrm{C}\right)$ in a certain evaluation period and $R H$ is the average air relative humidity (\%) in a certain evaluation period.

The Wind-Efficiency Index describes the human body's overall perception of wind, temperature and sunlight. Wind efficiency index is calculated by the following formula (Tang et al., 2008):

$$
K=-(10+10.45-V) \times(33-T)+8.55 S
$$

In the formula, $K$ is the Wind-Efficiency Index, $T$ is the average temperature $\left({ }^{\circ} \mathrm{C}\right)$ in a certain evaluation period, $V$ is the average wind speed $(\mathrm{m} / \mathrm{s})$ in a certain evaluation period and $S$ is the average sunshine duration $(\mathrm{h} / \mathrm{d})$ in a certain evaluation period.

The degree of climate comfort was evaluated by $I$ and $K$. When the two indexes are inconsistent, $K$ should be used in the winter half year, and $I$ should be used in the summer half year (Ma et al., 2011).

\section{Results and Analysis of Eco-Tourism Climate Resources}

\subsection{Basic Meteorological Elements}

\section{Temperature and Precipitation}

Temperature is one of the most sensitive meteorological elements that affect the human body. It plays an important role in the regulation of human body temperature and is one of the most concerned meteorological elements in people's daily life. The average annual temperature in Xingwen is $17.8^{\circ} \mathrm{C}$ based on the daily temperature observation data in the past 20 years. The coldest month of the year is January with an average temperature of $7.6^{\circ} \mathrm{C}$ while the hottest month is July with an average temperature of $27.1^{\circ} \mathrm{C}$.

The average seasonal temperature of spring, summer, autumn and winter in Xingwen is $18.1^{\circ} \mathrm{C}, 26.1^{\circ} \mathrm{C}, 18.3^{\circ} \mathrm{C}$ and $8.9^{\circ} \mathrm{C}$ while the temperature difference between adjacent seasons is basically around $8^{\circ} \mathrm{C}$. The seasonal differences of maximum and minimum temperatures are similar to the seasonal differences in the average temperature. Xingwen is affected by the monsoon climate with four distinct seasons.

Most of the average annual precipitation in Sichuan is between 400 and 1200 $\mathrm{mm}$. The basin area is generally between 800 to $1200 \mathrm{~mm}$. And Xingwen is located in the southern part of the basin where the annual precipitation is abundant.

According to the statistics of precipitation data, Xingwen has abundant precipitation and the number of precipitation days is also large. The average annual precipitation is $1095.8 \mathrm{~mm}$. February and December have the lowest average rainfall of $31 \mathrm{~mm}$ while July has the highest average rainfall of $191.3 \mathrm{~mm}$. The maximum one-day precipitation was $161.2 \mathrm{~mm}$ which occurred on August 29, 2009. The average annual rain days are 185.6 days, with the most (20.3 days) in 
October and the least (12.8 days) in August.

Xingwen not only has abundant precipitation, but also has excellent allocation of rain-heat resources (precipitation and temperature) on the time scale. The distribution of temperature and precipitation in each month of the year is generally changing simultaneously (Figure 1). The greatest advantage of year-round heat and rain configuration is in the spring. As the temperature in spring exceeds $10^{\circ} \mathrm{C}$ and increases gradually, the precipitation also gradually increases significantly. The average precipitation in February is $31 \mathrm{~mm}$, March $50.1 \mathrm{~mm}$, April $78.9 \mathrm{~mm}$, and in May the precipitation increased to $119.6 \mathrm{~mm}$. This provides excellent rain and heat conditions for natural plant growth in the spring, and there is very little drought during the spring.

\section{Wind, Relative Humidity and Sunshine Hours}

The annual average wind speed in Xingwen is $1.3 \mathrm{~m} / \mathrm{s}$, and the monthly average wind speed is stable around the average. Due to the influence of topography, the frequency of quiet winds in Xingwen reaches 36\%.

Xingwen is located in the southern edge of Sichuan Basin, which is under the water vapor channel that from the Indian Ocean and the South China Sea to the inland. The annual average relative humidity is $81 \%$, and the relative humidity varies from $76 \%$ to $87 \%$ in each month. The humidity in this area is higher in the winter because there is less sunshine and autumn rain often occurs. In the spring and after it, the humidity gradually decreases as the temperature rises and the sunshine increases.

The annual average sunshine hours in Xingwen are $999.2 \mathrm{~h}$, of which the sunshine hours in January-March and October-December are less than $80 \mathrm{~h}$. There are more sunshine hours from April to September, with an average of over $100 \mathrm{~h}$ per month (Figure 2).

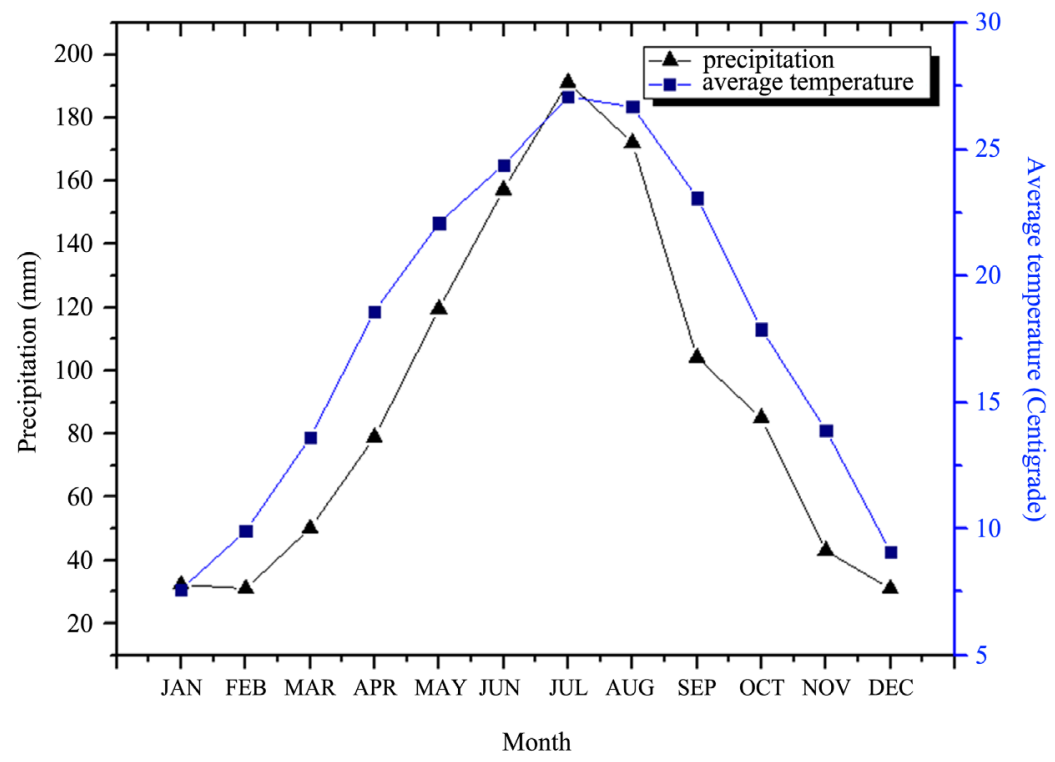

Figure 1. Monthly average precipitation and temperature. 


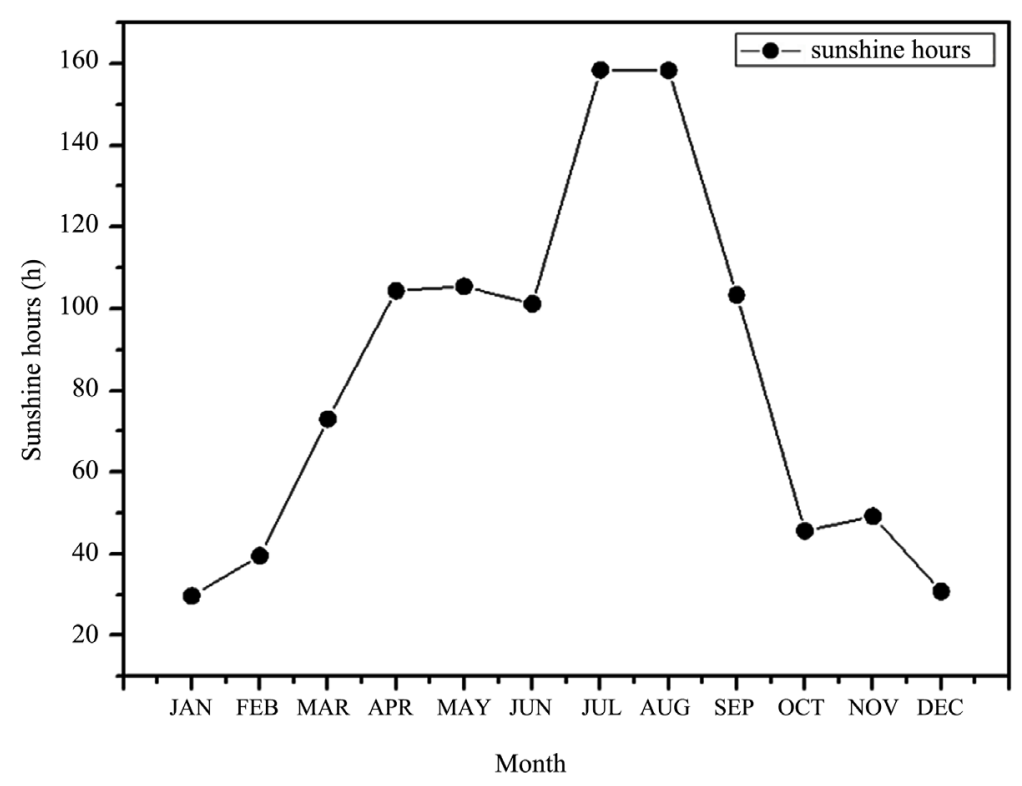

Figure 2. Monthly sunshine hours in Xingwen.

\subsection{Index of Climate Comfort}

By calculating the Temperature-Humidity Index (I) and Wind-Efficiency Index (K), the comfort level of human living environment in Xingwen can be evaluated in each month (Table 3).

The monthly changes of Index Grade of Climate Comfort of Human Living Environment were analyzed (Table 3). According to the Index Grade of Climate Comfort of Human Living Environment (Table 2), there are 6 months in which the Index of Climate Comfort of Xingwen reached Grade 3 (comfortable). The average comfortable period is from April to June and from August to October. The $I$ value ranges from 17.6 to 25.2 and the $K$ value ranges from -281 to -90 that indicating that healthy people feel comfortable at those period. In midsummer July, the Index of Climate Comfort level of Xingwen is Grade 4 (hot). However the $I$ value is 25.7 which is close to and slightly higher than Grade 3 (comfortable). Also compare to other places there is not any Stuffy Hot month in Xingwen which indicates that the healthy people felt a little heat but not too uncomfortable at that month there. March and November are early spring and late autumn, and the value of $I$ is between 13.7 and 13.9 and the value of $K$ is between -379 and -367 . In those months the Index of Climate Comfort of Xingwen is Grade 2 (chill) that the overall feeling is chill and less comfortable. From December to February, the $I$ value is between 8.2 and 10.3 and the $K$ value is between -496 and -455 . In winter the Index of Climate Comfort of Xingwen is Grade 1 (cold) that the overall feeling is cold and uncomfortable. Therefore, according to the comfort level, tourists feel the most comfortable from April to June and from August to October each year while march, July and November follow. In these months, the body feeling is more comfortable and the climate is very suitable for tourism. 
Table 3. Monthly index grade of climate comfort and how body feels in Xingwen.

\begin{tabular}{ccccc}
\hline & JAN & FEB & MAR & APR \\
\hline$I$ & 8.2 & 10.3 & 13.7 & 18 \\
Index Grade & -496 & -455 & -379 & -273 \\
Body feeling & Grade 1 & Grade 1 & Grade 2 & Grade 3 \\
\hline \multicolumn{1}{c}{ Cold } & Cold & Chill & Comfortable \\
\hline$I$ & MAY & JUN & JUL & AUG \\
\hline Index Grade & Grade 3 & Grade 3 & Grade 4 & Grade 3 \\
Body feeling & Comfortable & Comfortable & Hot & Comfortable \\
\hline & SEP & OCT & NOV & DEC \\
\hline$I$ & 22.2 & 17.6 & 13.9 & 9.5 \\
\hline$K$ & -176 & -281 & -367 & -463 \\
Index Grade & Grade 3 & Grade 3 & Grade 2 & Grade 1 \\
Body feeling & Comfortable & Comfortable & Chill & Cold \\
\hline
\end{tabular}

\subsection{NAI Concentration}

The negative oxygen ions (NAI) in the atmosphere are beneficial to the human body. The human body inhales negative oxygen ions, which can regulate the excitement of the nerve center, promote metabolism and improve blood circulation. Negative oxygen ions are also called "vitamins in the atmosphere". The content of negative oxygen ions in the air is affected by many factors, and the concentration is higher in parks, seashores, lakes, waterfalls and forests. Many studies have shown that the better the quality of the atmospheric environment, the higher the concentration of negative oxygen ions, the more beneficial to health (Table 4). In recent years, natural oxygen zone Eco-Tourism has gradually become a new trend of tourism development.

The monthly average NAI monitoring data at Feiwu Cave Station and Shoushan Lake Station were calculated in this study. The average monthly NAI concentration at Feiwu Cave is above $10,000 / \mathrm{cm}^{3}$, and the average monthly NAI concentration at Shoushan Lake Station is between $4000 / \mathrm{cm}^{3}$ to $11,000 / \mathrm{cm}^{3}$. The annual average NAI concentration of Xingwen is $11,415 / \mathrm{cm}^{3}$. It can be seen that the average concentration of negative oxygen ions in this area far exceeds the standard for clean air $\left(1000-1500 / \mathrm{cm}^{3}\right)$ proposed by the World Health Organization, and it has the effect of enhancing immunity and healing treatment for the human body.

The air is particularly fresh and the annual NAI level of the two monitoring stations in Xingwen is the highest level 7, which is very beneficial to human health (Table 5). Frequent cold air or abundant precipitation indirectly increases the concentration of NAI concentration in the area. Xingwen has superior NAI 
Table 4. NAI concentration and air quality level.

\begin{tabular}{ccc}
\hline NAI Concentration $\left(\right.$ number $\left./ \mathrm{cm}^{3}\right)$ & Level & Relationship With Health \\
\hline 500 & 1 & Unfavorable \\
$500-800$ & 2 & Normal \\
$800-1100$ & 3 & Somewhat Favorable \\
$1100-1400$ & 4 & Favorable \\
$1400-1700$ & 5 & Quite Advantageous \\
$1700-2000$ & 6 & Very Advantageous \\
$\geq 2000$ & 7 & Extremely Advantageous \\
\hline
\end{tabular}

Table 5. Monthly NAI concentration changes in Xingwen.

\begin{tabular}{ccccc}
\hline Month & $\begin{array}{c}\text { Feiwu Cave NAI } \\
\text { Concentration }\end{array}$ & $\begin{array}{c}\text { Shoushan Lake } \\
\text { NAI Concentration }\end{array}$ & Level & Air Freshness \\
\hline JAN & $10,087 / \mathrm{cm}^{3}$ & $19780 / \mathrm{cm}^{3}$ & 7 & Extremely Pure and Fresh \\
FEB & $8870 / \mathrm{cm}^{3}$ & $17075 / \mathrm{cm}^{3}$ & 7 & Extremely Pure and Fresh \\
MAR & $8585 / \mathrm{cm}^{3}$ & $15789 / \mathrm{cm}^{3}$ & 7 & Extremely Pure and Fresh \\
APR & $10,348 / \mathrm{cm}^{3}$ & $13877 / \mathrm{cm}^{3}$ & 7 & Extremely Pure and Fresh \\
MAY & $8748 / \mathrm{cm}^{3}$ & $14550 / \mathrm{cm}^{3}$ & 7 & Extremely Pure and Fresh \\
JUN & $8580 / \mathrm{cm}^{3}$ & $13516 / \mathrm{cm}^{3}$ & 7 & Extremely Pure and Fresh \\
JUL & $9509 / \mathrm{cm}^{3}$ & $12494 / \mathrm{cm}^{3}$ & 7 & Extremely Pure and Fresh \\
AUG & $9192 / \mathrm{cm}^{3}$ & $12425 / \mathrm{cm}^{3}$ & 7 & Extremely Pure and Fresh \\
SEP & $5590 / \mathrm{cm}^{3}$ & $15055 / \mathrm{cm}^{3}$ & 7 & Extremely Pure and Fresh \\
OCT & $9711 / \mathrm{cm}^{3}$ & $10750 / \mathrm{cm}^{3}$ & 7 & Extremely Pure and Fresh \\
NOV & $4294 / \mathrm{cm}^{3}$ & $15674 / \mathrm{cm}^{3}$ & 7 & Extremely Pure and Fresh \\
DEC & $6302 / \mathrm{cm}^{3}$ & $13164 / \mathrm{cm}^{3}$ & 7 & Extremely Pure and Fresh \\
\hline
\end{tabular}

conditions, which is conducive to carrying out ecological tourism activities such as forest recuperation, leisure and vacation. It is a "natural oxygen zone" with the superior natural conditions for building an NAI health care base.

\section{Conclusion}

The climate is mild, the precipitation is abundant and the seasonal variation trend of precipitation and heat is similar in the study area Xingwen. It is affected by the monsoon climate with four distinct seasons and the average annual temperature in Xingwen is $17.8^{\circ} \mathrm{C}$. The annual average precipitation is $1096 \mathrm{~mm}$, the annual average precipitation days are 186 days, the annual average relative humidity is $81 \%$, the annual average wind speed is $1.3 \mathrm{~m} / \mathrm{s}$, and the annual average sunshine hours are $999 \mathrm{~h}$. The results of Index of Climate Comfort show that the tourists feel the most comfortable from April to June and from August to October each year while March, July and November follow. In these months, the body feeling is more comfortable and the climate is more suitable for tourism. 
The air is extremely fresh in the study area. The concentration of NAI in Xingwen remains at the highest level 7 throughout the year. Overall, Xingwen has high-quality ecological climate resources that are conducive to the development of forest recuperation, leisure and vacation and other ecological tourism activities.

\section{Acknowledgements}

This study was co-financed by the Meteorological Local Standard Research Project of Sichuan Province (2020) and the Science and Technology Development Foundation of Sichuan Provincial Key Laboratory of Rainstorm Drought Flood Disasters in Plateau and Basin (No. SCQXKJQN202).

\section{Conflicts of Interest}

The authors declare no conflicts of interest regarding the publication of this paper.

\section{References}

Barradas, V. L. (1991). Air Temperature and Humidity and Human Comfort Index of Some City Parks of Mexico City. International Journal of Biometeorology, 35, 24-28. https://doi.org/10.1007/BF01040959

Gagge, A. P., Stolwijk, J. A. J., \& Nishi, Y. (1970). Analysis and Application in Environment Engineering. Copenhagen: Danish Technical Press.

Hougthton, F. C., \& Yaglou, C. P. (1923). Determining Equal Comfort Lines. Journal of the American Society of Heating and Ventilating Engineers, 29, 165-176.

Kalkstein, L. S., \& Valimont, K. M. (1986). An Evaluation of Summer Discomfort in the United States Using a Relative Climatological Index. Bulletin of the American Meteorological Society, 67, 842-848. https://doi.org/10.1175/1520-0477(1986)067<0842:AEOSDI>2.0.CO;2

Ma, L. J., Sun, G. N., Ma, Y. R., Cai, X. F., \& Hou, K. (2011). Analysis on Climate Comfort Change of Tourism in Beijing in the Past 50 Years. Journal of Arid Land Resources and Environment, 25, 161-166.

Nikolopoulou, M., \& Lykoudis, S. (2006). Thermal Comfort in Outdoor Urban Spaces: Analysis across Different European Countries. Building and Environment, 41, 1455-1470. https://doi.org/10.1016/j.buildenv.2005.05.031

Siple, P., \& Passel, C. F. (1945). Measurements of Dry Atmospheric Cooling in Subfreezing Temperatures. Proceedings of the American Philosophical Society, 89, 177-199.

Tang, Y., Feng, Z. M., \& Yang, Y. Z. (2008). Climate Suitability Assessment of Human Settlement Environment in China Based on Grid Scale. Resources Science, No. 5, 648-653.

Terjuny, W. H. (1966). Physiologic Climates of the Conterminous United States: A Bioclimatic Classification Based on Man. Annals of the Association of American Geographers, 56, 141-179. https://doi.org/10.1111/j.1467-8306.1966.tb00549.x

Thom, E. C. (1959). The Discomfort Index. Weatherwise, 12, 57-61. https://doi.org/10.1080/00431672.1959.9926960

Wang, S. G., Ma, P., Shang, K. Z., Zhang, Z. W., Li, X., Cheng, Y. F., Wang, Z. Q., Zhang, Y., Wang, J. Y., \& Dang, B. (2013). A Calculation Method for Human Comfort Based on Golden Section Method. Gansu: CN103106336A, 2013-05-15. 
Xu, D. H., \& Zhu, R. (2000). The Sensation of Human to Temperature \& Humility \& Wind Speed and the Clothing. Quarterly Journal of Applied Meteorlogy, 11, 432-441.

Yan, M. L., \& Shen, S. Q. (2005). Discussion on the Design Method of Environmental Meteorological Index. Meteorological Science and Technology, 33, 583-588.

Zhou, H. F. (1999). Discussion in Synthetic Index of Climatic Change Influence on $\mathrm{Hu}-$ man Health. Climatic and Environment al Research, 4, 121-126. 